\title{
Lithium induced Bruxism: A Case Report
}

\author{
Prashant Chaudhari ${ }^{1}$, Sagar Karia ${ }^{2}$, Nilesh Shah $^{3}$, Avinash De Sousa ${ }^{4}$ \\ ${ }^{1}$ Resident Doctor \\ ${ }^{2}$ Assistant Professor \\ ${ }^{3}$ Professor and Head \\ ${ }^{4}$ Research Associate and Consultant Psychiatrist \\ Department of Psychiatry, Lokmanya Tilak Municipal Medical College, Mumbai. \\ Corresponding author: Sagar Karia \\ Email-kariabhai117@gmail.com
}

\begin{abstract}
Lithium has been widely used in the management of bipolar disorder and is the gold standard for the management of mania. It has been used for over 7 decades now and a number of side effects have been reported with the drug. The notable side effects have been acne, skin reactions, thyroid problems and its effects on the renal system. We report a case in which a 18 year girl that developed bruxism due to lithium with raised serum lithium levels which stopped on stoppage of the drug.
\end{abstract}

Keywords: lithium, bruxism, teeth grinding.

(Paper received $-5^{\text {th }}$ August 2020, Peer review completed $-10^{\text {th }}$ August 2020)

(Accepted $-18^{\text {th }}$ August 2020)

\section{INTRODUCTION}

Lithium has been used for the past 7 decades as a drug of choice in the treatment of bipolar mood disorder [1]. It has a narrow therapeutic index with therapeutic range varying from $0.4-1.2 \mathrm{meq} / \mathrm{L}$ and with toxicity seen mostly beyond $1.5 \mathrm{meq} / \mathrm{L}$ [2]. Bruxism is defined as a parafunctional activity of stomatognathic system including clenching, bracing, gnashing, and grinding of the teeth' [3]. Some evidence suggests that one of the important proposed causes of bruxism is an alteration in neurotransmission in the brain [4]. The use of various psychotropic agents have long been associated with oral movement disorders such as bruxism, orofacial dystonia, oromandibular dyskinesia etc. and are related to extrapyramidal effects of antipsychotic drugs because of their antagonist activity on the dopaminergic receptors [5]. Lithium has been noted to cause orofacial dyskinesias, bruxism in few case studies resolved with anticholinergic drugs but there have been no biological explanations for why it occurs [6]. We report a case of an 18 years old girl that developed lithium induced bruxism which was correlated with elevated serum lithium levels and resolved after discontinuation of the drug and subsequent shifting to valproate as a mood stabilizer.

\section{CASE REPORT}

An 18 years old girl was diagnosed as having Bipolar I Mood Disorder and was taking treatment from our outpatient department since the past 2 years. She was well maintained on Lithium Carbonate 400mg once a day and Olanzapine 10mg in divided doses. There was an exacerbation in her symptoms in form of talking excessively, grandiose ideations and a reduced need for sleep. The dose of lithium was increased to $800 \mathrm{mg} /$ day in divided doses. Within 8 days of increasing the dose, she developed complaints of grinding of the teeth, throughout the day which would stop only when she would be asleep. This teeth grinding was 
present even while eating, speaking and even when her attention was distracted. Her behavioral complaints had reduced, and her mood symptoms were resolved with the increase in dose. The patient said that all efforts made to control the grinding, failed to control it. She also developed coarse tremors and gait disturbances. There was no evidence of rigidity, excessive salivation, slurring in speech or any other evidence of extrapyramidal reaction and on examination her physical examination and central nervous system examination was normal except for the findings mentioned above.

As her parents were worried and as the symptom was distressing to the patient she was admitted in our ward. Her Lithium was stopped immediately, and blood was sent for measuring serum Lithium levels. Divalproate Sodium $500 \mathrm{mg} /$ day was added, and olanzapine $10 \mathrm{mg}$ was continued as before. All other routine blood investigations were within normal limits. Even serum Creatinine Phosphokinase (CPK) levels was within normal range. Her serum Lithium level was $1.7 \mathrm{mEq} / \mathrm{L}$ (Therapeutic range $0.6-1.2 \mathrm{mEq} / \mathrm{L}$ ). Her bruxism improved over 8 days and she was $90 \%$ better. Her dose of Divalproate Sodium was increased to $1 \mathrm{gm} /$ day in divided doses. At the time of discharge, we repeated the serum Lithium levels which came down to $0.9 \mathrm{mEq} / \mathrm{L}$.

There was no history suggestive of similar complaints in the past. Her developmental history was unremarkable. A diagnosis of Lithium induced Bruxism was made owing to available evidence. The Naranjo's algorithm was applied and the score was +5 which indicated lithium to be a cause of the bruxism. [7] We offered a rechallenge with Lithium but the patient and her parents refused for the same, hence it was not done. A note was made about the same in patient's clinical record for future warning to clinicians that may handle the case. The patient is currently maintained on Divalproate Sodium $1 \mathrm{gm} /$ day and olanzapine $10 \mathrm{mg} /$ day both in divided doses.

\section{DISCUSSION}

Bruxism has been reported in literature with antipsychotics, SSRIs and lithium [8]. Although literature review reports a few cases of lithium induced bruxism, no known mechanism is provided or proposed [9]. In this case, bruxism in our patient was correlated with raised serum lithium levels and relief was noted on stopping lithium and thus decreased serum concentrations. The same was confirmed using Naranjo's algorithm. It is important for clinicians to be aware of this rare but distressing side effect of lithium as it is one of the most widely prescribed drugs for the maintenance of bipolar mood disorder and also due to huge array of differential diagnoses that are considered when bruxism arises. Lithium is a drug that has been widely over the past 5 decades in psychiatry and it is important that clinicians be aware of various side effects that may occur when the patient is on this drug. Prudent clinical monitoring and questioning will help in early detection and treatment of side effects when on Lithium therapy.

\section{Declaration of patient consent}

The authors certify that they have obtained all appropriate patient consent forms. The patient has consented for; his clinical information will be used to report in a journal. The patient also understands that his name and other initials will not be disclosed, and due efforts will be made to conceal his identity.

\section{REFERENCES}

1. Malhi GS, Tanious M, Das P, Coulston CM, Berk M. Potential mechanisms of action of lithium in bipolar disorder. CNS Drugs 2013;27(2):135-53.

2. Kessing LV, Vradi E, Andersen PK. Nationwide and population-based prescription patterns in bipolar disorder. Bipolar Disord 2016;18(2):174-82.

3. Reddy SV, Kumar MP, Sravanthi D, Mohsin AH, Anuhya V. Bruxism: a literature review. J Int Oral Health 2014;6(6):105-9.

4. Klasser GD, Rei N, Lavigne GJ. Sleep bruxism etiology: the evolution of a changing paradigm. J Can Dent Assoc 2015;81:12-4.

5. Falisi G, Rastelli C, Panti F, Maglione H, Quezada Arcega R. Psychotropic drugs and bruxism. Exp Opin Drug Safe 2014;13(10):1319-26. 
6. Melo G, Dutra KL, Rodrigues Filho R, Ortega AD, Porporatti AL, Dick B, Flores-Mir C, De Luca Canto G. Association between psychotropic medications and presence of sleep bruxism: A systematic review. J Oral Rehabil 2018;45(7):545-54.

7. Belhekar MN, Taur SR, Munshi RP. A study of agreement between the Naranjo algorithm and WHO-UMC criteria for causality assessment of adverse drug reactions. Indian J Pharmacol 2014;46(1):117-20.

8. Winocur E, Gavish A, Voikovitch M, Emodi-Perlman A, Eli I. Drugs and bruxism: a critical review. J Orofacial Pain 2003;17(2):99-111.

9. Clark GT, Ram S. Four oral motor disorders: bruxism, dystonia, dyskinesia and drug-induced dystonic extrapyramidal reactions. Dental Clin 2007;51(1):225-43.

\section{Acknowledgements - Nil \\ Conflict of Interest - Nil \\ Funding - Nil}

